\title{
Buku Penghubung Berbasis Android Menggunakan Metode Prototyping
}

http://dx.doi.org/10.28932/jutisi.v6i3.2993

\author{
Heri Maulana ${ }^{\bowtie \# 1}$, Kasmawi ${ }^{* 2}$, Depandi Enda ${ }^{\# 3}$ \\ ${ }^{\#} J u r u s a n$ Teknik Informatika, Politeknik Negeri Bengkalis \\ Jl. Bathin Alam, Sungai Alam Bengkalis Riau \\ ${ }^{1}$ herimaulana85egmail.com \\ ${ }^{3}$ depandienda@polbeng.ac.id \\ *Jurusan Teknik Informatika, Politeknik Negeri Bengkalis \\ Jl. Bathin Alam, Sungai Alam Bengkalis Riau \\ ${ }^{2}$ kasmawi@polbeng.ac. id
}

\begin{abstract}
The role of parents is very important in the education of their children, even though parents have entrusted their children to school. Parents also have a responsibility for continuing children's learning at home. Parents of course need information about their child's learning at school so that they guide learning at home in accordance with the lessons learned at school. In order for the information to be conveyed properly, SDN 04 Bengkalis uses a Buku Penghubung. Buku penghubung is used as a medium for communication between teachers and parents. However, the problem that arises from using it is the lack of interest of parents in using buku penghubung. Buku penghubung, also often left behind, easy to lose, and prone to damage because made of paper. This research aims to build an android-based buku penghubung application. The application features announcements, daily grades, list of lessons, and attendance. The method in this research is prototyping. The result of this research is an Android-based buku penghubung application that can be used by teachers and parents. Application testing uses black box testing and compatibility testing.
\end{abstract}

Keywords - Buku Penghubung; Android; Black Box; Compatibility.

\section{Pendahuluan}

Orang tua berperan penting sebagai faktor keberhasilan dalam kegiatan belajar mengajar. Orang tua adalah tanggung jawab utama dalam pendidikan dan prestasi belajar anak. Para orang tua yang akan menentukan masa depan anak, namun dalam keterbatasan dan peluang yang dimiliki oleh orang tua, maka mereka meminta pihak lain untuk membantu mendidik anak-anak. Pihak lain adalah guru di sekolah. Setelah anak-anak dititipkan di sekolah maka orang tua tetap bertanggung jawab untuk keberhasilan pendidikan anak mereka. Tanggung jawab orang tua antara lain dapat diwujudkan dengan membimbing kelangsungan anak belajar di rumah sesuai dengan program yang telah dipelajari anak di sekolah. Membimbing anak belajar di rumah dapat dilakukan dengan mengawasi dan membantu mengerjakan tugas sekolah [1]. Dalam proses bimbingan tentu dibutuhkan informasi mengenai kegiatan anak di sekolah, sejauh mana anak dapat memahami pelajaran dan apa kendala anak dalam proses belajar mengajar. Namun informasi ini tidak didapatkan karena dalam proses belajar mengajar anak tidak didampingi oleh orang tuanya. Masalah tersebut juga terjadi pada Sekolah Dasar Negeri (SDN) 04 Kecamatan Bengkalis yang berlokasi di Jl. Arif RahmanBengkalis. Agar orang tua mendapatkan informasi mengenai kegiatan anaknya di sekolah, SDN 04 Bengkalis menggunakan buku penghubung guru dan orang tua.

Buku penghubung adalah tempat pencatatan seputar kegiatan yang dilakukan murid setiap hari di sekolah disertai catatan untuk orang tua di rumah. Dengan buku penghubung orang tua mendapatkan informasi mengenai kegiatan anaknya di sekolah, seperti informasi perkembangan anaknya, pemahaman anak mengenai pembelajaran, dan informasi perilaku anaknya di sekolah [2]. Permasalahan yang timbul dari penggunaan buku penghubung adalah kurangnya minat orang tua dalam menggunakan buku penghubung. Masalah lain yang ditemui adalah murid sering lupa membawa buku penghubung, selain itu buku penghubung juga rentan mengalami kerusakan dan hilang. Penelitian ini bertujuan untuk membangun aplikasi buku penghubung berbasis android menggunakan metode prototyping. Aplikasi ini dapat digunakan oleh guru dan orang tua murid kelas satu SDN 04 Bengkalis untuk mempermudah komunikasi.

\section{TINJAUAN PUSTAKA}

Masalah yang menjadi topik penelitian oleh Firmansyah, Suryatiningsih, dan Siswanto [2] yaitu wali kelas kesulitan untuk berkomunikasi dengan orang tua melalui buku penghubung. Hal ini dikarenakan orang tua lebih senang 
menggunakan handphone dan membuat grup untuk berkomunikasi daripada menggunakan buku penghubung. Masalah lain yang timbul adalah murid yang sering lupa membawa buku penghubung dan buku juga rentan rusak atau hilang. Hasil dari penelitian adalah sebuah aplikasi buku penghubung berbasis web sebagai media komunikasi antara orang tua dan pihak sekolah secara online.

Penelitian yang dilakukan oleh oleh Rahmani, Haryono, dan Purwanti [3] bertujuan untuk pengembangan media komunikasi berbasis Short Message service (SMS) Gateway dan Mobile Web. Metode yang digunakan adalah Research and Development. Hasil dari penelitian adalah media komunikasi buku penghubung berbasis SMS Gateway dan Mobile Web.

Penelitian oleh Utomo [4] mengangkat masalah mengenai orang tua yang masih mendapati kesulitan dalam memantau proses belajar mengajar anak mereka di sekolah, orang tua juga tidak dapat memantau proses akademik anaknya dan hanya dapat menerima hasil akhir mengenai prestasi atau nilai pada saat pembagian raport. Metode yang digunakan oleh peneliti adalah Systems Development Life Cycle (SDLC). Penelitian ini menghasilkan sistem yang mampu memudahkan pihak sekolah dalam memantau dan mengontrol absensi serta informasi nilai akademik.

Penelitian oleh Laili, Subroto, dan Mustafa [5] dilakukan di Pondok Pesantren Al Iman Mutilan yang memiliki santri dengan asal daerah dari dalam maupun luar kota, sehingga banyak wali santri yang kesulitan untuk memantau perkembangan anaknya dikarenakan jarangnya berkunjung ke pesantren. Untuk mengetahui perkembangan anaknya, wali dari santri menggunakan telepon sebagai media pemantauan. Akan tetapi menggunakan telepon dinilai kurang efisien karena tidak semua informasi tersampaikan dengan baik dan benar. Hasil dari penelitian ini adalah sebuah sistem informasi buku penghubung berbasis web yang memudahkan pihak pesantren dalam menyampaikan informasi mengenai santri kepada wali santri.

Mengacu pada empat penelitian sebelumnya maka dapat disimpulkan bahwa perlunya buku penghubung agar informasi dapat tersampaikan dengan jelas antara pihak sekolah dan orang tua. Keterbaruan dari penelitian ini adalah aplikasi akan dibuat berbasis android yang dapat dipasang pada perangkat android guru dan orang tua.

Android adalah sebuah sistem operasi yang awalnya dikembangkan oleh perusahaan kecil bernama Silicon Valley dengan nama Android Inc. Selanjutnya android diambil alih oleh Google pada tahun 2005 dan mencanangkannya sebagai aplikasi "Open Source." Sebagai konsekuensinya siapapun boleh memanfaatkannya dengan gratis, termasuk dalam hal kode sumber yang digunakan untuk menyusun sistem operasi tersebut [6].

Ionic adalah framework yang dikhususkan untuk menggabungkan aplikasi mobile hybrid dengan Hypertext Markup Language (HTML), Cascading Style Sheets (CSS) dan AngularJS. Ionic menggunakan Node.js Syntactically Awesome StyleSheets (SASS), AngularJS sebagai engine- nya. Ionic dilengkapi dengan komponen-komponen CSS seperti button, list, card, form, grid, tabs, dan yang lainnya. Ionic juga sebuah framework yang dapat dirilis dalam lebih dari satu flatform atau cross-platform [7].

\section{METODE DAN PERANCANGAN}

Penelitian ini menggunakan metode prototyping. Prototyping adalah salah satu metode pengembangan perangkat lunak yang digunakan sebagai versi awal sebuah perangkat lunak untuk menampilkan sebuah konsep, melakukan percobaan terhadap opsi desain dan mencari tahu lebih lanjut mengenai masalah serta kemungkinan solusinya [8].

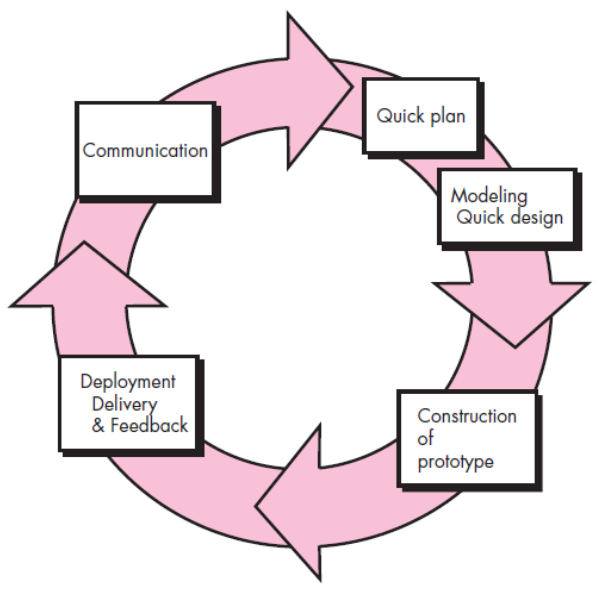

Gambar 1. Prototyping oleh Pressman [9]

Gambar 1 merupakan tahapan prototyping yang memiliki empat tahap. Tahap tersebut yaitu:

a. Communication

Merupakan tahap di mana pengembang dan pelanggan bertemu dan saling berinteraksi untuk mendefinisikan tujuan dari perangkat lunak yang akan dibuat. Pada penelitian ini dilakukan komunikasi bersama pihak sekolah SDN 04 Bengkalis untuk meminta penjelasan mengenai format buku penghubung, cara penggunaan buku penghubung, kendala penggunaan buku penghubung, dan informasi lainnya. Hasil dari communication adalah sebuah kebutuhan fungsional buku penghubung yang terdiri dari fungsi pengumuman, fungsi penilaian, fungsi daftar pelajaran, fungsi percakapan, dan fungsi absensi. Kebutuhan non fungsional dari buku penghubung yaitu dari sisi usability perangkat dapat dipasang di perangkat android, sisi portability system dapat diakses di manapun dengan perangkat mobile berbasis android dan dukungan internet untuk akses database, sisi reliability sistem memiliki dua login yaitu guru dan orang tua.

\section{b. Quick Plan and Modeling Quick Design}

Tahap ini dilakukan setelah gambaran umum perangkat lunak secara umum diketahui. Pembuatan 
rancangan secara cepat berdasarkan pada representasi aspek-aspek perangkat lunak yang akan terlihat oleh pengguna. Tahap ini dilakukan pembuatan use case diagram.

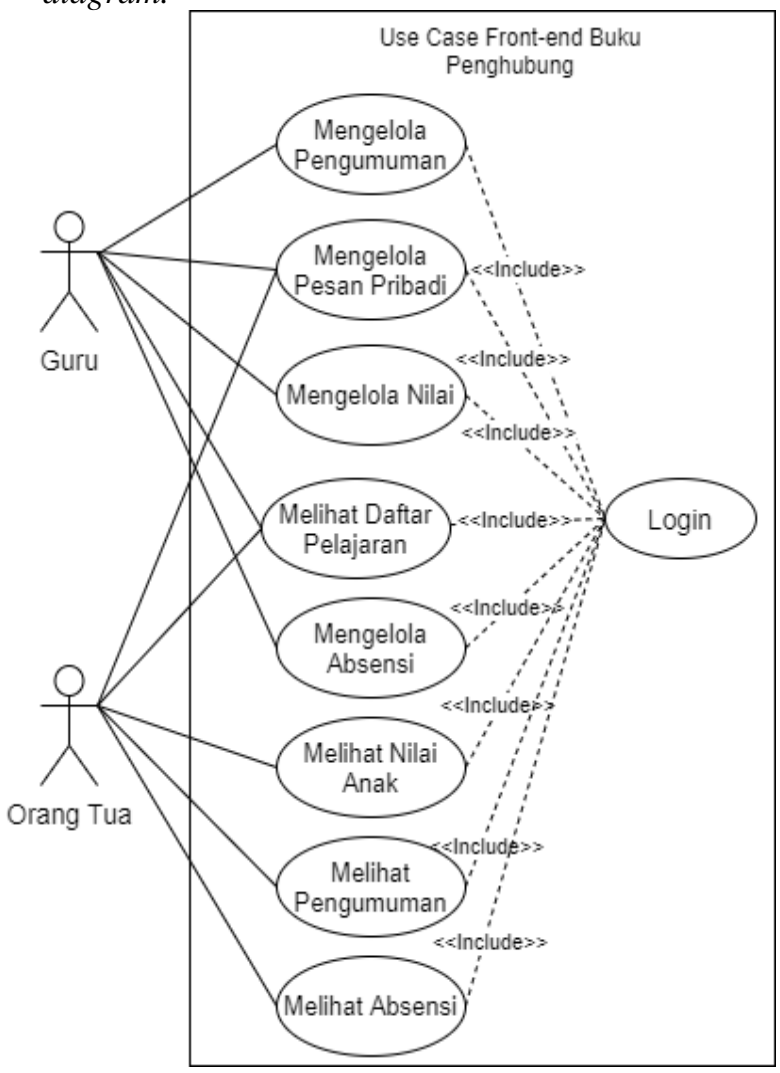

Gambar 2. Use Case Diagram Guru dan Orang Tua

Gambar 2 merupakan diagram yang menggambarkan aksi yang dilakukan aktor terhadap sistem. Terdapat dua aktor berbeda yaitu guru dan orang tua. Guru dapat melakukan pengelolaan pengumuman, mengelola pesan pribadi, mengelola nilai, melihat daftar pelajaran, dan mengelola absensi. Orang tua dapat melihat pengumuman yang dikirim oleh guru, mengelola pesan pribadi, melihat nilai anak, melihat daftar pelajaran anak, dan melihat absensi anak.

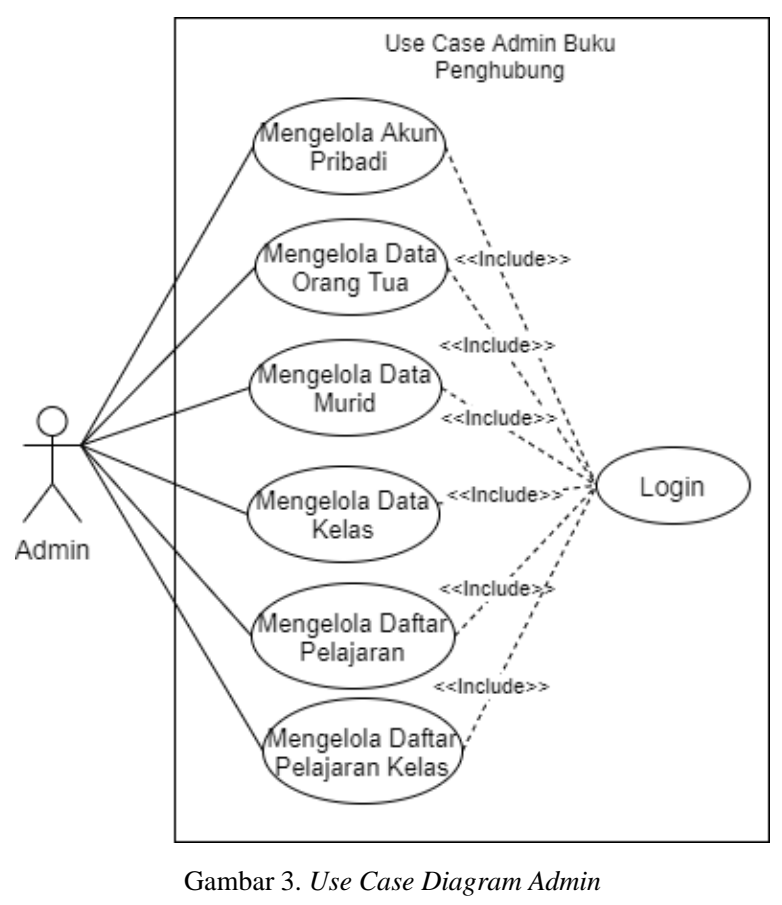

Gambar 3 merupakan use case diagram khusus admin. Admin memiliki akses untuk mengelola akun pribadi, mengelola akun orang tua, mengelola akun guru, mengelola data kelas, mengelola daftar pelajaran, dan mengelola daftar pelajaran kelas.

\section{c. Construction of Prototype}

Setelah diketahui tujuan umum dan rancangan dari perangkat lunak, maka tahap ini dilakukan dengan membuat prototype. Hasil perancangan prototype buku penghubung adalah sebagai berikut:

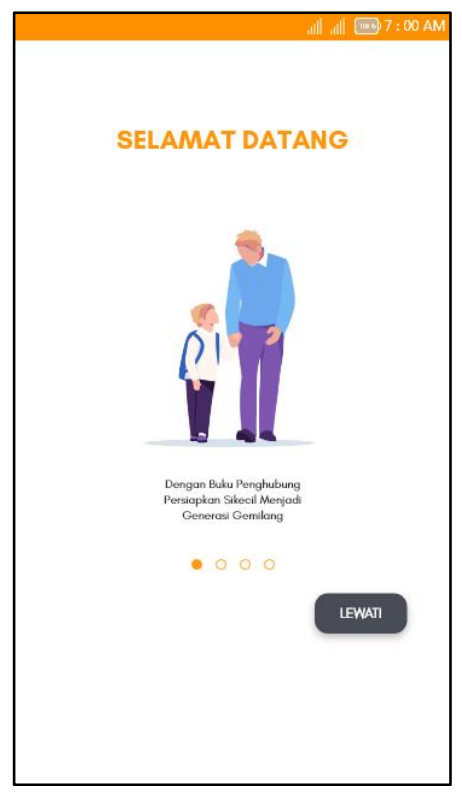

Gambar 4. Slider Images 
Gambar 4 merupakan prototype slider images. Tampilan ini yang akan muncul saat aplikasi berhasil terpasang di ponsel pengguna.

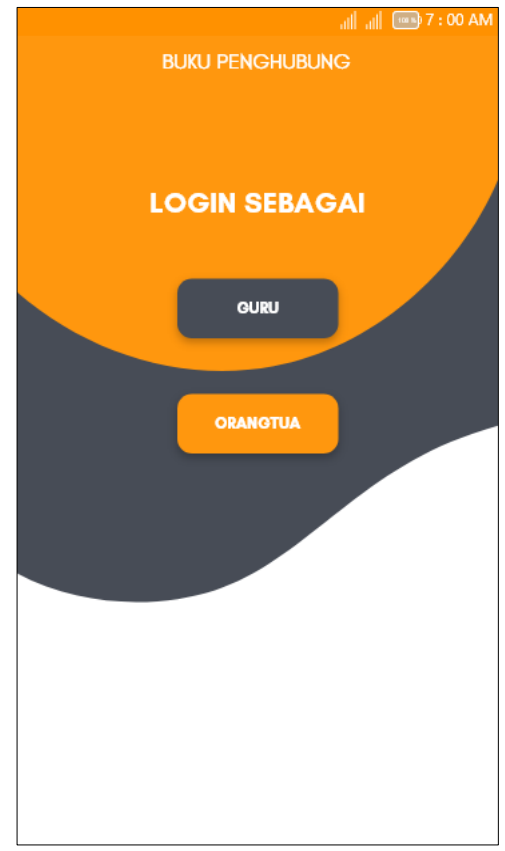

Gambar 5. Pilihan Login

Gambar 5 merupakan prototype pilihan login, terdapat dua pilihan yaitu guru dan orang tua. Orang tua dapat memilih tombol login sebagai orang tua, dan guru dapat memilih tombol login guru.

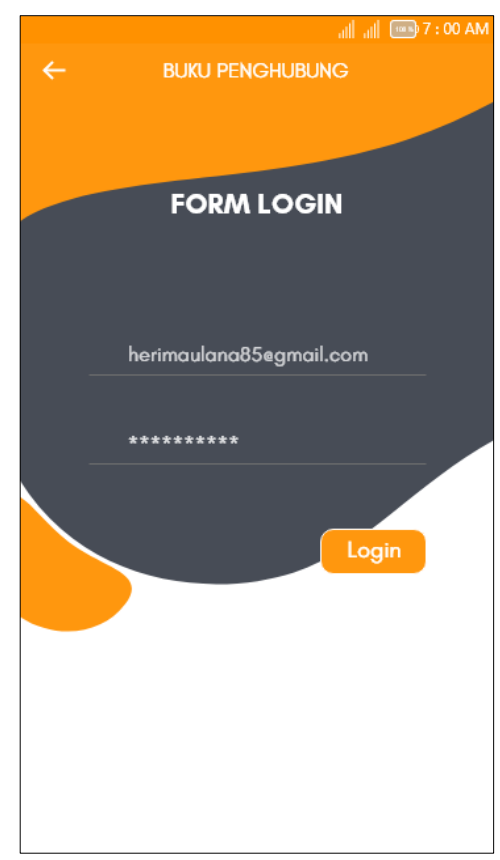

Gambar 6. Form Login
Gambar 6 merupakan prototype tampilan form login. Terdapat dua field yang harus diisi yaitu email dan password. Setelah berhasil login maka pengguna akan dialihkan ke halaman beranda seperti gambar 7 .

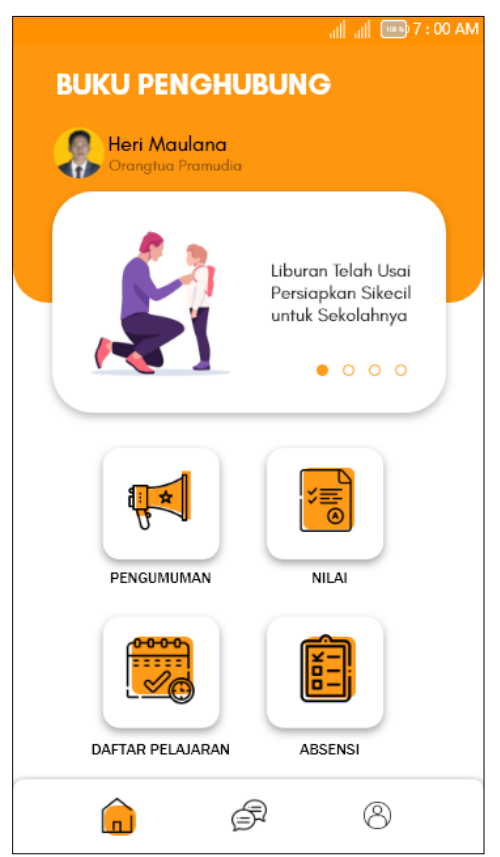

Gambar 7. Beranda

Gambar 7 merupakan prototype halaman beranda. Terdapat empat tombol dalam bentuk card pada tampilan ini yaitu, tombol pengumuman, nilai, daftar pelajaran, dan absensi.

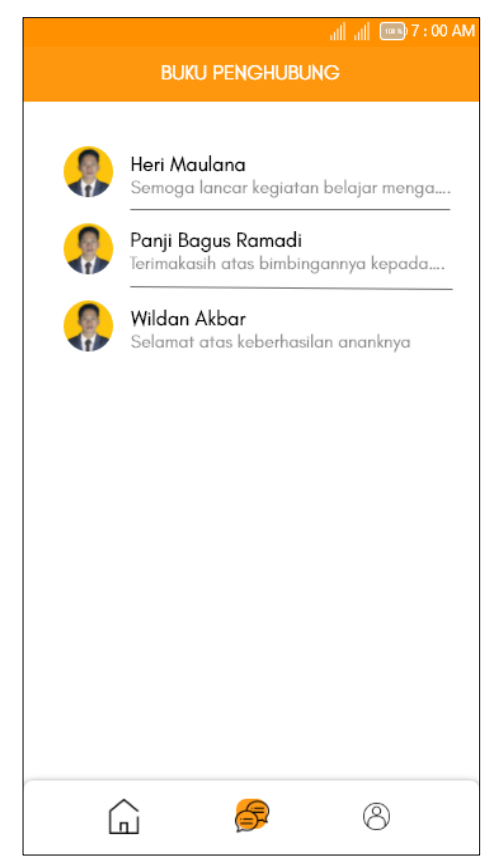

Gambar 8. Percakapan 
Gambar 8 merupakan prototype tampilan halaman percakapan. Halaman berguna untuk melakukan komunikasi antara orang tua dan guru.

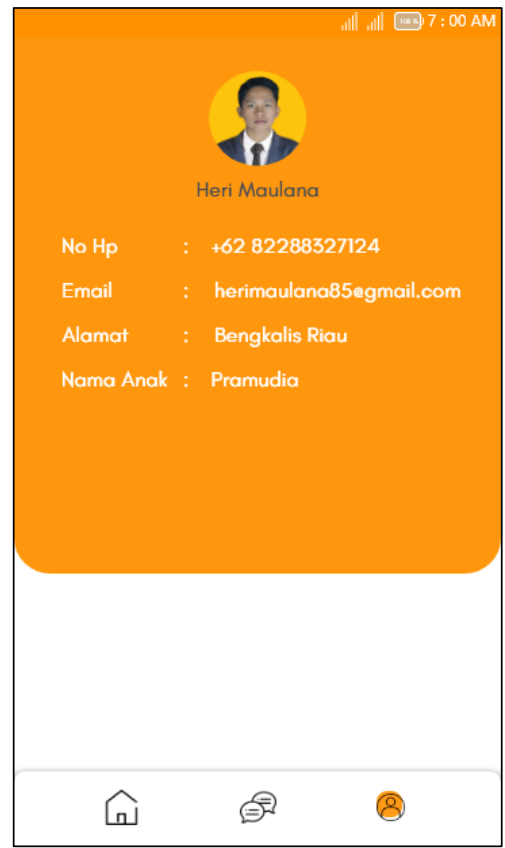

Gambar 9. Profile

Gambar 9 merupakan prototype tampilan halaman profile. Halaman ini akan menampilkan informasi akun pengguna yang melakukan login.

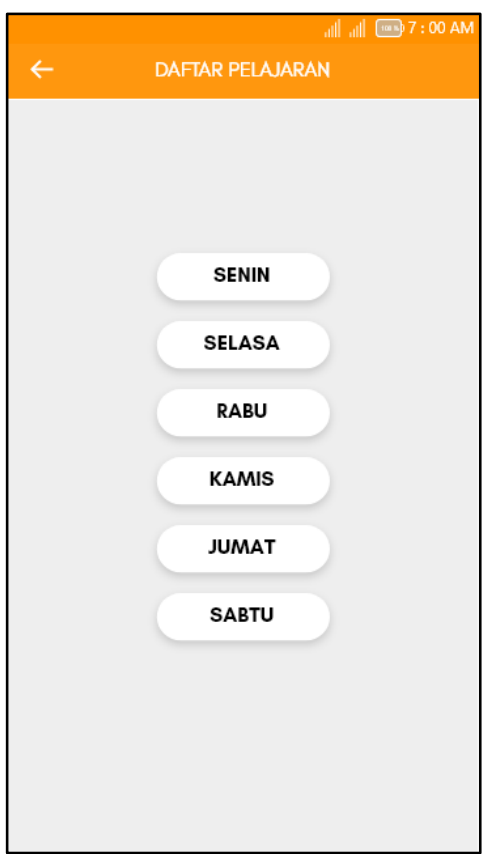

Gambar 10. Daftar Pelajaran

Gambar 10 merupakan prototype tampilan halaman daftar pelajaran kelas. Halaman ini akan menampilkan daftar pelajaran harian yang dapat dilihat oleh guru dan orang tua.

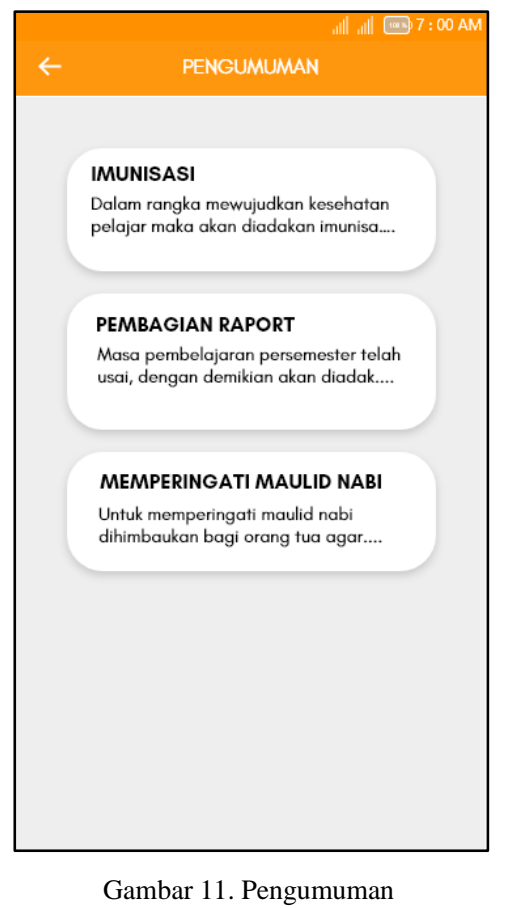

Gambar 11 merupakan prototype tampilan halaman pengumuman. Halaman ini akan menampilkan pengumuman yang dikirim oleh guru.

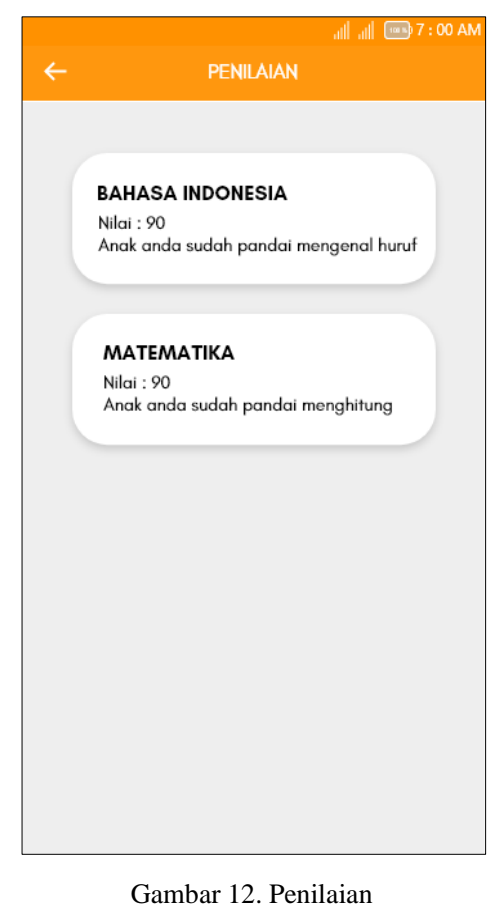

Gambar 12 merupakan prototype tampilan halaman penilaian. Guru akan melakukan input nilai murid sehingga orang tua dapat mengetahui nilai harian anaknya. 


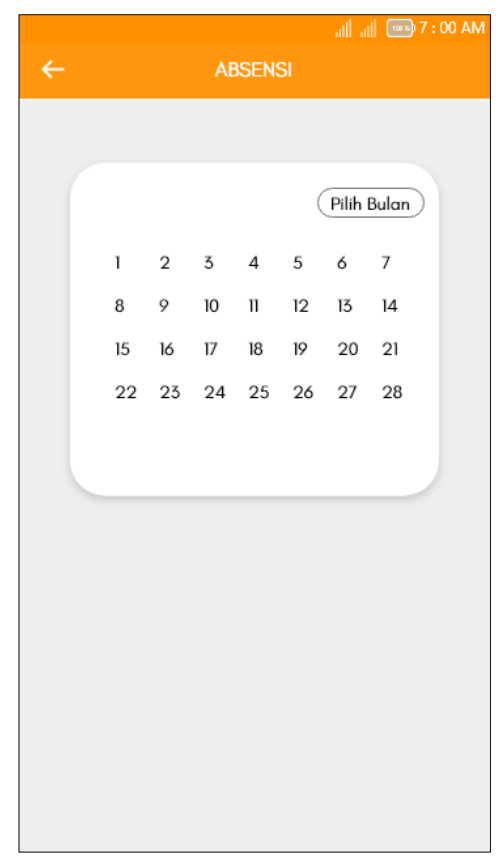

Gambar 13. Absensi

Gambar 13 merupakan prototype tampilan halaman absensi. Guru akan melakukan absensi setiap kali melakukan proses belajar mengajar. Orang tua dapat melihat absensi harian anaknya pada halaman absensi ini.

\section{d. Deployment Delivery \& Feedback}

Memberikan prototype kepada pengguna untuk dilakukan evaluasi dan mendapatkan feedback mengenai tampilan yang telah dibuat. Pada penelitian ini evaluasi dilakukan dengan menggunakan kuesioner untuk mendapatkan pendapat pengguna mengenai prototype yang telah dibuat. Kuesioner disebarkan kepada pihak guru dan orang tua. Setiap butir pertanyaan dinilai menggunakan skala likert yang memiliki skor 1 sampai dengan 5, di mana skor 5 untuk jawaban Sangat Setuju, skor 4 untuk jawaban Setuju, skor 3 untuk jawaban Kurang Setuju, skor 2 untuk jawaban Tidak Setuju, dan skor 1 untuk jawaban Sangat Tidak Setuju [10].

TABEL I

BUTIR PERTANYAAN KUESIONER

\begin{tabular}{|c|c|c|c|c|c|c|}
\hline \multirow{2}{*}{ Komponen } & \multirow{2}{*}{ Butir Pertanyaan } & \multicolumn{5}{|c|}{ Skor } \\
\hline & & 1 & 2 & 3 & 4 & 5 \\
\hline $\begin{array}{l}\text { Prototype } \\
\text { Slider Images }\end{array}$ & $\begin{array}{l}\text { Apakah Tampilan slider } \\
\text { images anda sukai? }\end{array}$ & & & & & \\
\hline \multirow[b]{2}{*}{$\begin{array}{l}\text { Prototype } \\
\text { Pilihan Login }\end{array}$} & $\begin{array}{l}\text { Apakah Tampilan pilihan } \\
\text { Login anda sukai? }\end{array}$ & & & & & \\
\hline & $\begin{array}{l}\text { Apakah anda memahami } \\
\text { fungsi dari setiap tombol } \\
\text { pada halaman pilihan } \\
\text { login? }\end{array}$ & & & & & \\
\hline
\end{tabular}

\begin{tabular}{|c|c|c|c|c|c|c|}
\hline \multirow{2}{*}{ Komponen } & \multirow{2}{*}{ Butir Pertanyaan } & \multicolumn{5}{|c|}{ Skor } \\
\hline & & 1 & 2 & 3 & 4 & 5 \\
\hline $\begin{array}{l}\text { Prototype } \\
\text { Form Login }\end{array}$ & $\begin{array}{l}\text { Apakah tampilan form } \\
\text { login di atas anda sukai? }\end{array}$ & & & & & \\
\hline \multirow[b]{2}{*}{$\begin{array}{l}\text { Prototype } \\
\text { Beranda }\end{array}$} & $\begin{array}{lr}\text { Apakah } & \text { tampilan } \\
\text { Halaman } & \text { Beranda anda } \\
\text { sukai? } & \end{array}$ & & & & & \\
\hline & $\begin{array}{lr}\text { Apakah informasi yang } \\
\text { ada pada tampian } \\
\text { Halaman } \\
\text { tersebut mudah untuk } \\
\text { dipahami? }\end{array}$ & & & & & \\
\hline \multirow[b]{2}{*}{$\begin{array}{l}\text { Prototype } \\
\text { Pengumuman }\end{array}$} & $\begin{array}{lr}\text { Apakah } & \text { Halaman } \\
\text { pengumuman anda sukai? }\end{array}$ & & & & & \\
\hline & $\begin{array}{ll}\text { Apakah } & \text { Halaman } \\
\text { pengumuman } & \\
\text { menampilkan } & \text { informasi } \\
\text { dengan jelas? } & \\
\end{array}$ & & & & & \\
\hline \multirow{2}{*}{$\begin{array}{l}\text { Prototype } \\
\text { Daftar } \\
\text { Pelajaran }\end{array}$} & $\begin{array}{l}\text { Apakah Halaman Daftar } \\
\text { Pelajaran anda sukai? }\end{array}$ & & & & & \\
\hline & $\begin{array}{l}\text { Apakah Halaman Daftar } \\
\text { pelajaran menampilkan } \\
\text { informasi dengan jelas? }\end{array}$ & & & & & \\
\hline \multirow{2}{*}{$\begin{array}{l}\text { Prototype } \\
\text { Absensi }\end{array}$} & $\begin{array}{l}\text { Apakah Halaman Absensi } \\
\text { anda sukai? }\end{array}$ & & & & & \\
\hline & $\begin{array}{l}\text { Apakah Halaman Absensi } \\
\text { menampilkan informasi } \\
\text { yang jelas? }\end{array}$ & & & & & \\
\hline \multirow[b]{2}{*}{$\begin{array}{l}\text { Prototype } \\
\text { Profile }\end{array}$} & $\begin{array}{l}\text { Apakah Halaman Profil } \\
\text { anda sukai? }\end{array}$ & & & & & \\
\hline & $\begin{array}{l}\text { Apakah tampilan halaman } \\
\text { Profil menampilkan } \\
\text { informasi yang jelas? }\end{array}$ & & & & & \\
\hline \multirow[b]{2}{*}{$\begin{array}{l}\text { Prototype } \\
\text { Percakapan }\end{array}$} & $\begin{array}{l}\text { Apakah Halaman Chat } \\
\text { anda sukai? }\end{array}$ & & & & & \\
\hline & $\begin{array}{l}\text { Apakah tampilan halaman } \\
\text { Chat menampilkan } \\
\text { informasi yang jelas? }\end{array}$ & & & & & \\
\hline \multirow[b]{2}{*}{$\begin{array}{l}\text { Prototype } \\
\text { Penilaian }\end{array}$} & $\begin{array}{l}\text { Apakah Halaman } \\
\text { Penilaian anda sukai? }\end{array}$ & & & & & \\
\hline & $\begin{array}{l}\text { Apakah Tampilan } \\
\text { Penilaian dapat dengan } \\
\text { mudah dipahami? }\end{array}$ & & & & & \\
\hline Pewarnaan & $\begin{array}{l}\text { Dari keseluruhan } \\
\text { tampilan aplikasi apakah } \\
\text { warna tampilan sudah } \\
\text { sesuai? }\end{array}$ & & & & & \\
\hline \multirow{3}{*}{ Learnability } & $\begin{array}{l}\text { Apakah aplikasi mudah } \\
\text { dipahami? }\end{array}$ & & & & & \\
\hline & $\begin{array}{l}\text { Apakah aplikasi memuat } \\
\text { informasi yang anda } \\
\text { butuhkan? }\end{array}$ & & & & & \\
\hline & $\begin{array}{lr}\text { Dapatkah } & \text { anda } \\
\text { memahami alur } & \text { ali } \\
\text { penggunaan aplikasi? }\end{array}$ & & & & & \\
\hline Tata letak & $\begin{array}{l}\text { Apakah tata letak tombol, } \\
\text { icon, dan komponen } \\
\text { lainnya sudah sesuai? }\end{array}$ & & & & & \\
\hline Fungsional & $\begin{array}{lrr}\text { Apakah } & \text { aplikasi } & \text { sudah } \\
\text { memiliki fungsi } & \text { yang } \\
\text { sama } & \text { dengan } & \text { buku } \\
\end{array}$ & & & & & \\
\hline
\end{tabular}




\begin{tabular}{|l|l|l|l|l|l|l|}
\hline \multirow{2}{*}{ Komponen } & \multicolumn{2}{|c|}{ Butir Pertanyaan } & \multicolumn{5}{|c|}{ Skor } \\
\cline { 3 - 7 } & $\begin{array}{l}\text { penghubung sebelumnya } \\
\text { yang terbentuk dari } \\
\text { kertas? }\end{array}$ & & & & & \\
\hline
\end{tabular}

Tabel I merupakan butir pertanyaan yang digunakan untuk mengevaluasi prototype. Feedback yang didapat dari penyebaran kuesioner kepada guru dan orang tua adalah tiga orang dari guru dan sembilan orang dari orang tua. Jumlah ini sudah memenuhi kebutuhan karena sudah mendapat tanggapan dari dua aktor yang dibutuhkan yaitu guru dan orang tua. dalam penelitiannya dilakukan evaluasi prototype terhadap lima orang yang memenuhi kriteria kebutuhan [11].

Setelah didapatkan feedback dilakukan pengolahan data untuk menentukan prototype layak dijadikan acuan pembangunan aplikasi atau perlu perbaikan lagi. Pengolahan data menggunakan rumus Teknik analisis persentase (\%)[12].

$P=\frac{f}{N} \times 100$

Dimana :

$\mathrm{P}=$ Nilai persentase

$\mathrm{f}=$ Frekuensi jawaban

$\mathrm{N}=$ Total frekuensi

TABEL II

HASIL EVALUASI PROTOTYPE SISI GURU

\begin{tabular}{|l|c|}
\hline \multicolumn{1}{|c|}{ Butir Pertanyaan } & Persentase \\
\hline Apakah Tampilan slider images anda sukai? & $100 \%$ \\
\hline Apakah Tampilan pilihan Login anda sukai? & $93 \%$ \\
\hline $\begin{array}{l}\text { Apakah anda memahami fungsi dari setiap } \\
\text { tombol pada halaman pilihan login? }\end{array}$ & $87 \%$ \\
\hline Apakah tampilan form login di atas anda sukai? & $87 \%$ \\
\hline Apakah tampilan Halaman Beranda anda sukai? & $100 \%$ \\
\hline $\begin{array}{l}\text { Apakah informasi yang ada pada tampian } \\
\text { Halaman Beranda tersebut mudah untuk } \\
\text { dipahami? }\end{array}$ & $87 \%$ \\
\hline Apakah Halaman pengumuman anda sukai? & $87 \%$ \\
\hline $\begin{array}{l}\text { Apakah Halaman pengumuman menampilkan } \\
\text { informasi dengan jelas? }\end{array}$ & $87 \%$ \\
\hline Apakah Halaman Daftar Pelajaran anda sukai? & $87 \%$ \\
\hline $\begin{array}{l}\text { Apakah Halaman Daftar pelajaran menampilkan } \\
\text { informasi dengan jelas? }\end{array}$ & $87 \%$ \\
\hline Apakah Halaman Absensi anda sukai? & $93 \%$ \\
\hline $\begin{array}{l}\text { Apakah Halaman Absensi menampilkan } \\
\text { informasi yang jelas? }\end{array}$ & $87 \%$ \\
\hline Apakah Halaman Profil anda sukai? & $100 \%$ \\
\hline $\begin{array}{l}\text { Apakah tampilan halaman Profil menampilkan } \\
\text { informasi yang jelas? }\end{array}$ & $93 \%$ \\
\hline Apakah Halaman Chat anda sukai? & $93 \%$ \\
\hline $\begin{array}{l}\text { Apakah tampilan halaman Chat menampilkan } \\
\text { informasi yang jelas? }\end{array}$ & $87 \%$ \\
\hline Apakah Halaman Penilaian anda sukai? & $87 \%$ \\
\hline $\begin{array}{l}\text { Apakah Tampilan Penilaian dapat dengan mudah } \\
\text { dipahami? }\end{array}$ & $80 \%$ \\
\hline
\end{tabular}

\begin{tabular}{|l|c|}
\hline \multicolumn{1}{|c|}{ Butir Pertanyaan } & Persentase \\
\hline $\begin{array}{l}\text { Dari keseluruhan tampilan aplikasi apakah warna } \\
\text { tampilan sudah sesuai? }\end{array}$ & $80 \%$ \\
\hline Apakah aplikasi mudah dipahami? & $87 \%$ \\
\hline $\begin{array}{l}\text { Apakah aplikasi memuat informasi yang anda } \\
\text { butuhkan? }\end{array}$ & $87 \%$ \\
\hline $\begin{array}{l}\text { Dapatkah anda memahami alur penggunaan } \\
\text { aplikasi? }\end{array}$ & $80 \%$ \\
\hline $\begin{array}{l}\text { Apakah tata letak tombol, icon, dan komponen } \\
\text { lainnya sudah sesuai? }\end{array}$ & $87 \%$ \\
\hline $\begin{array}{l}\text { Apakah aplikasi sudah memiliki fungsi yang } \\
\text { sama dengan buku penghubung sebelumnya yang } \\
\text { terbentuk dari kertas? }\end{array}$ & $87 \%$ \\
\hline
\end{tabular}

Tabel II merupakan hasil dari pengolahan data jawaban responden dari guru menggunakan rumus teknik analisis persentase, selanjutnya dilakukan perhitungan rata-rata untuk mendapatkan nilai rata-rata jawaban.

$$
\begin{aligned}
& \text { Rata }- \text { rata kelayakan }=\frac{\text { Jumlah Nilai Kelayakan }}{\text { Jumlah Pertanyaan }} \\
& \text { Rata }- \text { rata kelayakan }=\frac{2130 \%}{24} \\
& \text { Rata }- \text { rata kelayakan }=88,75 \%
\end{aligned}
$$

TABEL III

HASIL EVALUASI PROTOTYPE SISI ORANG TUA

\begin{tabular}{|l|c|}
\hline \multicolumn{1}{|c|}{ Butir Pertanyaan } & Persentase \\
\hline Apakah Tampilan slider images anda sukai? & $78 \%$ \\
\hline Apakah Tampilan pilihan Login anda sukai? & $80 \%$ \\
\hline $\begin{array}{l}\text { Apakah anda memahami fungsi dari setiap } \\
\text { tombol pada halaman pilihan login? }\end{array}$ & $84 \%$ \\
\hline $\begin{array}{l}\text { Apakah tampilan form login di atas anda } \\
\text { sukai? }\end{array}$ & $84 \%$ \\
\hline $\begin{array}{l}\text { Apakah tampilan Halaman Beranda anda } \\
\text { sukai? }\end{array}$ & $84 \%$ \\
\hline $\begin{array}{l}\text { Apakah informasi yang ada pada tampian } \\
\text { Halaman Beranda tersebut mudah untuk } \\
\text { dipahami? }\end{array}$ & $80 \%$ \\
\hline Apakah Halaman pengumuman anda sukai? & $80 \%$ \\
\hline $\begin{array}{l}\text { Apakah Halaman pengumuman menampilkan } \\
\text { informasi dengan jelas? }\end{array}$ & $78 \%$ \\
\hline $\begin{array}{l}\text { Apakah Halaman Daftar Pelajaran anda } \\
\text { sukai? }\end{array}$ & $82 \%$ \\
\hline $\begin{array}{l}\text { Apakah Halaman Daftar pelajaran } \\
\text { menampilkan informasi dengan jelas? }\end{array}$ & $82 \%$ \\
\hline Apakah Halaman Absensi anda sukai? & $84 \%$ \\
\hline $\begin{array}{l}\text { Apakah Halaman Absensi menampilkan } \\
\text { informasi yang jelas? }\end{array}$ & $84 \%$ \\
\hline Apakah Halaman Profil anda sukai? & $84 \%$ \\
\hline $\begin{array}{l}\text { Apakah tampilan halaman } \\
\text { menampilkan informasi yang jelas? }\end{array}$ & $82 \%$ \\
\hline Apakah Halaman Chat anda sukai? & $78 \%$ \\
\hline $\begin{array}{l}\text { Apakah tampilan halaman Chat menampilkan } \\
\text { informasi yang jelas? }\end{array}$ & $75 \%$ \\
\hline Apakah Halaman Penilaian anda sukai? & $78 \%$ \\
\hline $\begin{array}{l}\text { Apakah Tampilan Penilaian dapat dengan } \\
\text { mudah dipahami? }\end{array}$ & $78 \%$ \\
\hline $\begin{array}{l}\text { Dari keseluruhan tampilan aplikasi apakah } \\
\text { warna tampilan sudah sesuai? }\end{array}$ & $78 \%$ \\
\hline
\end{tabular}




\begin{tabular}{|l|c|}
\hline \multicolumn{1}{|c|}{ Butir Pertanyaan } & Persentase \\
\hline Apakah aplikasi mudah dipahami? & $80 \%$ \\
\hline $\begin{array}{l}\text { Apakah aplikasi memuat informasi yang anda } \\
\text { butuhkan? }\end{array}$ & $80 \%$ \\
\hline $\begin{array}{l}\text { Dapatkah anda memahami alur penggunaan } \\
\text { aplikasi? }\end{array}$ & $75 \%$ \\
\hline $\begin{array}{l}\text { Apakah tata letak tombol, icon, dan } \\
\text { komponen lainnya sudah sesuai? }\end{array}$ & $78 \%$ \\
\hline $\begin{array}{l}\text { Apakah aplikasi sudah memiliki fungsi yang } \\
\text { sama dengan buku penghubung sebelumnya } \\
\text { yang terbentuk dari kertas? }\end{array}$ & $78 \%$ \\
\hline
\end{tabular}

Tabel III merupakan hasil dari pengolahan jawaban responden dari orang tua menggunakan rumus teknik analisis persentase. Selanjutnya dilakukan pencarian ratarata dari semua komponen pertanyaan sebagai berikut:

$$
\begin{aligned}
& \text { Rata }- \text { rata kelayakan }=\frac{\text { Jumlah Nilai Kelayakan }}{\text { Jumlah Pertanyaan }} \\
& \text { Rata }- \text { rata kelayakan }=\frac{1924 \%}{24} \\
& \text { Rata }- \text { rata kelayakan }=80,17 \%
\end{aligned}
$$

Setelah mendapatkan rata-rata dari feedback responden maka nilai tersebut dibandingkan dengan tabel kelayakan. Hasil perbandingan tersebut yang akan menentukan apakah prototyping layak digunakan atau tidak.

TABEL IV

HASIL EVALUASI PROTOTYPE SISI GURU

\begin{tabular}{|c|c|}
\hline Kategori & Kelayakan \\
\hline Sangat Layak & $81 \%-100 \%$ \\
\hline Layak & $61 \%-80 \%$ \\
\hline Cukup Layak & $41 \%-60 \%$ \\
\hline Tidak Layak & $21 \%-40 \%$ \\
\hline Sangat Tidak Layak & $<21 \%$ \\
\hline
\end{tabular}

Sesuai tabel IV maka prototype sisi guru dengan rata-rata $88,75 \%$ dikategorikan sebagai sangat layak untuk dijadikan acuan pembuatan aplikasi. Rata-rata nilai jawaban untuk prototype sisi orang tua sebesar $80,17 \%$ dengan kategori layak, dengan demikian prototype layak untuk dijadikan acuan pembuatan aplikasi buku penghubung.

Selain menggunakan butir pertanyaan dengan jawaban berupa skor skala likert, disediakan juga satu form untuk menerima masukan dari prototype yang telah dibuat. Hasil perubahan yang beracuan dari masukan responden dapat dilihat pada gambar 15 .

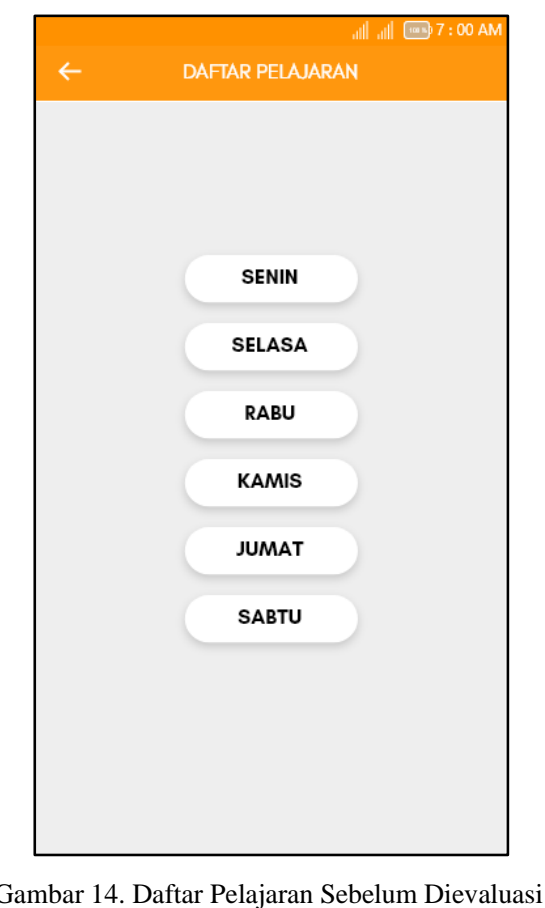

Gambar 14 merupakan prototype awal tampilan halaman daftar pelajaran. Prototype ini dilakukan perubahan agar setiap daftar pelajaran langsung tampil perhari tanpa melakukan klik pada hari. Hasil perubahan tampilan dapat dilihat pada gambar 15 .

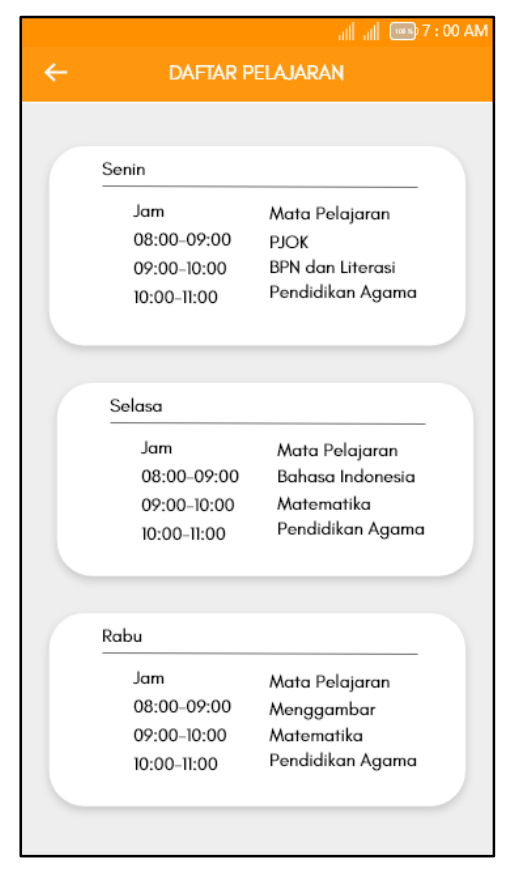

Gambar 15. Daftar Pelajaran Setelah Dievaluasi

Gambar 15 merupakan prototype hasil evaluasi sesuai dengan keinginan pengguna yaitu dengan menampilkan secara langsung daftar pelajaran perhari. 


\section{HASIL DAN PENGUJIAN}

Hasil dari penelitian ini merupakan aplikasi buku penghubung berbasis android yang memiliki fitur pengumuman, percakapan, penilaian, daftar pelajaran, dan absensi.

Pengujian aplikasi dilakukan menggunakan metode black box testing. Black box testing merupakan pengujian yang dilakukan untuk memastikan fungsional dari aplikasi berjalan sesuai perancangan. Pengujian menggunakan black box testing terfokus pada spesifikasi fungsional perangkat lunak. Tester dapat mendefinisikan kondisi input untuk melakukan testing pada spesifikasi fungsional program [13].

TABEL V

PENGUJiAn FITUR PENGUMUMAN

\begin{tabular}{|c|c|c|c|}
\hline \multicolumn{4}{|c|}{ Kasus dan Hasil Uji Coba pada fitur pengumuman sisi guru } \\
\hline Kasus Uji & $\begin{array}{c}\text { Hasil yang } \\
\text { diharapkan }\end{array}$ & $\begin{array}{c}\text { Hasil } \\
\text { pengamatan }\end{array}$ & Kesimpulan \\
\hline $\begin{array}{l}\text { Melakukan } \\
\text { klik pada } \\
\text { tombol } \\
\text { pengumuman } \\
\text { untuk } \\
\text { membuka } \\
\text { menu } \\
\text { pengumuman. }\end{array}$ & $\begin{array}{l}\text { Mengarahkan } \\
\text { ke halaman } \\
\text { pengumuman. }\end{array}$ & $\begin{array}{l}\text { Halaman } \\
\text { pengumuman } \\
\text { terbuka. }\end{array}$ & Berhasil \\
\hline $\begin{array}{l}\text { Menambah } \\
\text { pengumuman } \\
\text { dengan cara } \\
\text { melakukan } \\
\text { klik tombol } \\
\text { tambah pada } \\
\text { sudut kanan } \\
\text { bawah } \\
\text { halaman } \\
\text { pengumuman. }\end{array}$ & $\begin{array}{l}\text { Menampilkan } \\
\text { halaman form } \\
\text { tambah } \\
\text { pengumuman. }\end{array}$ & $\begin{array}{l}\text { Menampilkan } \\
\text { form halaman } \\
\text { tambah } \\
\text { pengumuman. }\end{array}$ & Berhasil \\
\hline $\begin{array}{l}\text { Melakukan } \\
\text { klik pada } \\
\text { simpan data } \\
\text { tanpa } \\
\text { melakukan } \\
\text { pengisian } \\
\text { pada form. }\end{array}$ & $\begin{array}{l}\text { Menampilkan } \\
\text { pesan error, } \\
\text { bahwa form } \\
\text { harus diisi. }\end{array}$ & $\begin{array}{l}\text { Pesan error } \\
\text { form harus } \\
\text { diisi muncul. }\end{array}$ & Berhasil \\
\hline $\begin{array}{l}\text { Melakukan } \\
\text { pengisian } \\
\text { pada form } \\
\text { yang } \\
\text { disediakan } \\
\text { dan menekan } \\
\text { tombol } \\
\text { simpan. }\end{array}$ & $\begin{array}{l}\text { Data } \\
\text { pengumuman } \\
\text { tersimpan dan } \\
\text { dialihkan ke } \\
\text { halaman } \\
\text { pengumuman. }\end{array}$ & $\begin{array}{l}\text { Pengumuman } \\
\text { berhasil } \\
\text { disimpan dan } \\
\text { dialihkan ke } \\
\text { halaman } \\
\text { pengumuman. }\end{array}$ & Berhasil \\
\hline $\begin{array}{l}\text { Melihat detail } \\
\text { pengumuman } \\
\text { dengan cara } \\
\text { melakukan } \\
\text { klik pada } \\
\text { salah satu } \\
\text { pengumuman. }\end{array}$ & $\begin{array}{l}\text { Menampilkan } \\
\text { detail } \\
\text { pengumuman } \\
\text { pada halaman } \\
\text { detail } \\
\text { pengumuman. }\end{array}$ & $\begin{array}{l}\text { Halaman } \\
\text { detail } \\
\text { pengumuman } \\
\text { terbuka dan } \\
\text { detail } \\
\text { pengumuman } \\
\text { tampil. }\end{array}$ & Berhasil \\
\hline
\end{tabular}

\begin{tabular}{|c|c|c|c|}
\hline \multicolumn{4}{|c|}{ Kasus dan Hasil Uji Coba pada fitur pengumuman sisi guru } \\
\hline Kasus Uji & $\begin{array}{c}\text { Hasil yang } \\
\text { diharapkan }\end{array}$ & $\begin{array}{c}\text { Hasil } \\
\text { pengamatan }\end{array}$ & Kesimpulan \\
\hline $\begin{array}{l}\text { Melakukan } \\
\text { edit data } \\
\text { dengan cara } \\
\text { menekan } \\
\text { tombol edit } \\
\text { pada detail } \\
\text { pengumuman, } \\
\text { selanjutnya } \\
\text { melakukan } \\
\text { edit data pada } \\
\text { form edit } \\
\text { data. }\end{array}$ & $\begin{array}{l}\text { Menampilkan } \\
\text { halaman form } \\
\text { edit data. } \\
\text { Data hasil } \\
\text { edit tersimpan } \\
\text { pada data } \\
\text { base. }\end{array}$ & $\begin{array}{l}\text { Halaman } \\
\text { form edit } \\
\text { pengumuman } \\
\text { muncul dan } \\
\text { hasil edit } \\
\text { tersimpan. }\end{array}$ & Berhasil \\
\hline $\begin{array}{l}\text { Hapus data } \\
\text { pengumuman } \\
\text { dengan cara } \\
\text { melakukan } \\
\text { klik pada } \\
\text { tombol hapus } \\
\text { di halaman } \\
\text { detail } \\
\text { pengumuman. }\end{array}$ & $\begin{array}{l}\text { Muncul pesan } \\
\text { peringatan } \\
\text { untuk } \\
\text { memberi tahu } \\
\text { user apabila } \\
\text { data dihapus } \\
\text { tidak dapat } \\
\text { dikembalikan } \\
\text { lagi. }\end{array}$ & $\begin{array}{l}\text { Pesan } \\
\text { peringatan } \\
\text { hapus } \\
\text { muncul, saat } \\
\text { ditekan Ya } \\
\text { data terhapus, } \\
\text { jika Tidak } \\
\text { data tidak } \\
\text { terhapus. }\end{array}$ & Berhasil \\
\hline
\end{tabular}

Tabel V merupakan pengujian black box pada fitur pengumuman. Hasil pengujian yaitu semua fungsi telah berjalan sesuai dengan peracangan. Fitur lain seperti daftar pelajaran, penilaian, absensi, dan percakapan juga dilakukan pengujian menggunakan black box testing dengan hasil semua fungsi berjalan sesuai dengan perancangan.

TABEL VI

PENGUJIAN COMPATIBILITY

\begin{tabular}{|c|c|c|c|}
\hline No & Alat Uji & Spesifikasi & Hasil \\
\hline 1 & $\begin{array}{l}\text { Smartphone } \\
\text { Xiaomi } \\
\text { Redmi } \\
\text { Note 5A }\end{array}$ & $\begin{array}{l}\text { Android } 10 \text { (Android } \\
\text { Q), Revenge v } 3.2 \text {. } \\
\text { Chipset Qualcomm } \\
\text { MSM8940 } \\
\text { Snapdragon } 435 \text { (28 } \\
\text { nm). } \\
\text { CPU Octa-core } 1.4 \mathrm{GHz} \\
\text { Cortex-A53. } \\
\text { GPU Adreno 505 } \\
\text { Internal 16GB RAM } \\
\text { 2GB. }\end{array}$ & $\begin{array}{l}\text { Aplikasi } \\
\text { berhasil } \\
\text { terpasang dan } \\
\text { semua fitur } \\
\text { berjalan } \\
\text { sesuai dengan } \\
\text { fungsinya. }\end{array}$ \\
\hline 2 & $\begin{array}{l}\text { Smartphone } \\
\text { Oppo A37 }\end{array}$ & $\begin{array}{l}\text { Android 5.1 (Lollipop), } \\
\text { ColorOS } 3 \text {. } \\
\text { Chipset Qualcomm } \\
\text { MSM8916 Snapdragon } \\
410 \text { (28 nm) } \\
\text { CPU Quad-core } 1.2 \\
\text { GHz Cortex-A53 } \\
\text { GPU Adreno } 306 \\
\text { Internal 16GB RAM } \\
\text { 2GB. }\end{array}$ & $\begin{array}{l}\text { Aplikasi } \\
\text { berhasil } \\
\text { terpasang dan } \\
\text { semua fitur } \\
\text { berjalan } \\
\text { sesuai dengan } \\
\text { fungsinya. }\end{array}$ \\
\hline 3 & $\begin{array}{l}\text { Smartphone } \\
\text { Xiaomi } \\
\text { Redmi } \\
\text { Note 6A }\end{array}$ & $\begin{array}{l}\text { OS Android } 8.1 \text { (Oreo), } \\
\text { MIUI } 11 . \\
\text { Chipset Mediatek } \\
\text { MT6761 Helio A22 (12 }\end{array}$ & $\begin{array}{l}\text { Aplikasi } \\
\text { berhasil } \\
\text { terpasang dan } \\
\text { semua fitur }\end{array}$ \\
\hline
\end{tabular}




\begin{tabular}{|c|c|c|c|}
\hline No & Alat Uji & Spesifikasi & Hasil \\
\hline & & $\begin{array}{l}\mathrm{nm}) . \\
\text { CPU Quad-core } 2.0 \\
\text { GHz Cortex-A53. } \\
\text { GPU PowerVR GE8320. } \\
\text { Internal 16GB RAM } \\
\text { 2GB. }\end{array}$ & $\begin{array}{l}\text { berjalan } \\
\text { sesuai dengan } \\
\text { fungsinya. }\end{array}$ \\
\hline 4 & $\begin{array}{l}\text { Smartphone } \\
\text { Oppo A5 } \\
2020\end{array}$ & $\begin{array}{l}\text { OS Android 9.0 (Pie), } \\
\text { ColorOS 6.1. } \\
\text { Chipset Qualcomm } \\
\text { SDM665 Snapdragon } \\
665(11 \mathrm{~nm}) . \\
\text { CPU Octa-core (4x2.0 } \\
\text { GHz Kryo 260 Gold \& } \\
\text { 4x1.8 GHz Kryo } 260 \\
\text { Silver). } \\
\text { GPU Adreno 610. } \\
\text { Internal 64GB RAM } \\
\text { 3GB. }\end{array}$ & $\begin{array}{l}\text { Aplikasi } \\
\text { berhasil } \\
\text { terpasang dan } \\
\text { semua fitur } \\
\text { berjalan } \\
\text { sesuai dengan } \\
\text { fungsinya. }\end{array}$ \\
\hline 5 & $\begin{array}{l}\text { Smartphone } \\
\text { Honor } 9 \\
\text { Lite }\end{array}$ & $\begin{array}{l}\text { OS Android } 8.0 \text { (Oreo), } \\
\text { EMUI 9.1. } \\
\text { Chipset Kirin } 659 \text { (16 } \\
\text { nm). } \\
\text { CPU Octa-core }(4 \times 2.36 \\
\text { GHz Cortex-A53 \& } \\
\text { 4x1.7 GHz Cortex-A53). } \\
\text { GPU Mali-T830 MP2. } \\
\text { Internal 32GB RAM } \\
\text { 3GB }\end{array}$ & $\begin{array}{l}\text { Aplikasi } \\
\text { berhasil } \\
\text { terpasang dan } \\
\text { semua fitur } \\
\text { berjalan } \\
\text { sesuai dengan } \\
\text { fungsinya. }\end{array}$ \\
\hline 6 & $\begin{array}{l}\text { Smartphone } \\
\text { Xiaomi } \\
\text { Redmi } 5\end{array}$ & $\begin{array}{l}\text { OS Android 7.1.2 } \\
\text { (Nougat), MIUI } 11 . \\
\text { Chipset Qualcomm } \\
\text { SDM450 Snapdragon } \\
450(14 \mathrm{~nm}) . \\
\text { CPU Octa-core } 1.8 \mathrm{GHz} \\
\text { Cortex-A53 } \\
\text { GPU Adreno 506. } \\
\text { Internal 16GB RAM } \\
\text { 2GB }\end{array}$ & $\begin{array}{l}\text { Aplikasi } \\
\text { berhasil } \\
\text { terpasang dan } \\
\text { semua fitur } \\
\text { berjalan } \\
\text { sesuai dengan } \\
\text { fungsinya. }\end{array}$ \\
\hline
\end{tabular}

Tabel VI merupakan hasil dari pengujian compatibility, hasil dari pengujian ini yaitu aplikasi buku penghubung berhasil dipasang di perangkat android dengan Operational System (OS) android Lolipop, Marsmallow, Oreo, Pie, dan android Q.

\section{KESIMPULAN DAN SARAN}

Berdasarkan hasil evaluasi prototype menggunakan kuesioner yang disebar kepada guru dan orang tua dari siswa kelas satu SDN 04 Bengkalis, feedback yang didapat dari penyebaran kuesioner yaitu sebanyak 3 guru dan 9 orang tua. Hasil evaluasi prototype sebesar $88,75 \%$ sisi guru dengan kategori sangat layak dan $80,17 \%$ sisi orang tua dengan kategori layak. Dengan demikian prototype dapat dijadikan acuan pembuatan aplikasi buku penghubung. Fitur-fitur yang dibuat menambah nilai guna aplikasi seperti penilaian harian untuk mengetahui nilai harian anak serta pemahamannya terhadap pembelajaran. Pengujian sistem dilakukan dengan metode black box testing dengan hasil semua fungsi sistem berjalan sesuai rancangan serta pengujian menggunakan compatibility testing dengan hasil aplikasi dapat terpasang pada android OS Lolipop, Marsmallow, Oreo, Pie, dan android Q. Aplikasi dapat dipasang pada ponsel guru dan orang tua sehingga dapat mengatasi masalah sebelumnya pada buku penghubung berbahan kertas yang rentan rusak, hilang, dan tertinggal. Saran untuk penelitian selanjutnya agar menerapkan fungsi trigger pada database agar transfer data menjadi real time serta menerapkan notifikasi.

\section{UCAPAN TERIMA KASIH}

Ucapan Terimakasih kepada ibu $\mathrm{Hj}$. Nurzairina S.Pd sebagai kepala sekolah SDN 04 Bengkalis, ibu Hasanah.Hs, S.Pd.SD, ibu Nuryanisma, S.Pd.SD, dan ibu Hj. Elnaledy, S.Pd.SD sebagai guru kelas satu SDN 04 Bengkalis, serta orang tua murid kelas satu SDN 04 Bengkalis yang telah membantu dalam proses penelitian ini.

\section{DAFTAR PUSTAKA}

[1] D.R. Fauzha. (2018) Bagaimana Peran Orangtua Terhadap Prestasi Belajar Anak? [Online]. Tersedia: https://www.kompasiana.com/dindarfz/5addfb85 caf7db132707b443/bagaimana-peran-orangtua-terhadap-prestasibelajar-anak?page $=$ all.

[2] H. Firmansyah, Suryatiningsih, \& B. Siswanto, "Aplikasi Buku Penghubung SD Ar-Rafi Berbasis Web," e-Proceeding of Applied Science, 2017, p. 87-110.

[3] M. A. C Rahmani, Haryono, \& E. Purwanti, "Pengembangan Media Komunikasi Buku Penghubung Berbasis SMS Gateway dan Mobile Web," Innovative Journal of Curriculum and Educational Technology, vol. 6, pp. 72-78, 2017.

[4] B. Utomo, "Sisitem Pemantauan Siswa Sekolah Berbasis Web: Studi Kasus di Pondok Pesantren Darul Muttaqin," Jurnal Online Mahasiswa, vol. 1, pp. 1-7, 2017.

[5] A. M. Laili, I. M. I. Subroto, \& Mustafa, "Sistem Informasi Penghubung Pembelajaran Santri Berbasis Web Pondok Pesantren Al Iman Muntilan," Jurnal Transistor Elektro dan Informatika (TRANSISTOR EI), vol. 2, pp. 143-153, 2017.

[6] A. Kadir, From Zero to A Pro-Pemrograman Aplikasi Android, Yogyakarta: Andi, 2013.

[7] A. S. Wahyunu. (2016) Apa Itu Ionic Framework. [Online]. Tersedia: https://www.codepolitan.com/apa-itu-ionic-framework57baac4756622-17924.

[8] D.Purnomo, "Model Prototyping Pada Pengembangan Sistem Informasi," JIMP - Jurnal Informatika Merdeka Pasuruan, vol. 2 , pp. 54-61, 2017.

[9] R.S. Pressman, Rekayasa Perangkat Lunak:Pendekatan Praktis, Edisi 7, Yogyakarta: Andi, 2012.

[10] Zulkiplih, Syahrul, \& J. M. Parenreng, "Pengembangan Aplikasi Pariwisata Sulawesi Barat Berbasis Android," JESSI, vol. 1, pp. 48 56, 2020.

[11] H. Southall, M. Marmion, \& A. Davies, “Adapting Jake Knapp's Design Sprint Approach for AR/VR Applications in Digital Heritage," in Augmented Reality and Virtual Reality, Springer, pp. 59-70, 2019.

[12] A. P. Halomoan, Z. Harmen, \& N. Sandra, "Penilaian Supervisor Jasa Konstruksi Terhadap Penguasaan Ilmu Kuantiti Surveying Mahasiswa Teknik Sipil FT-UNP Yang Melaksanakan Pengalaman Lapangan Industri (PLI) Di Kota Padang," CIVED ISSN 2302-3341, vol. 3, pp. 460-467, 2015.

[13] Y. Susanto, A. Utomo, \& D. S. Perbawa, "Pengujian Aplikasi Website Menggunakan Black Box Testing Boundary Value Analysis (Studi Kasus : Aplikasi website praktekdokter)," Jurnal SAINSTECH Politeknik Indonusa Surakarta, vol. 5, pp. 52-57, 2018. 